the remarks afcer equation $(12 \cdot 44)$ may give the erroneous impression that no series expansion can be based on the "virial" relation for the pressure. There are also chapters on black-body radiation and solutions.

The last section begins with the eighteenth chapter on the Boltzmann transport equation and $\mathrm{H}$-theorem, the apparent paradox of deriving irreversible behaviour from the time-reversible equations of mechanics being illustrated by the Kac ring model. A discussion of the relaxation spectrum of the linearized Boltzmann equation introduces the relaxation time approach to non-equilibrium problems. Three chapters on transport phenomena in various media follow. There is a treatment of fluctuations and Brownian motion including a careful derivation of the WienerKhinchin theorem, and the last chapter covers the Nyquist theorem and Onsager's relations.

The more difficult sections are "starred" with the suggestion that "students of average preparation" can omit them, although it would be a pity for any serious student to miss, say, Chapters 12 and 18 . Chapters in classical thermodynamics are also marked and it is suggested that "cursory reading should be adequate for well prepared students". Some of the material in these chapters, however (for example, Carathéodory's theory), is not elementary.

This book can be warmly recommended for good third year undergraduates and for research students, and most lecturers in the subject will find a great deal to interest them here.

G. M. BELL

\section{HIGH FLYING SURVEY}

Space Research VII

Edited by R. L. Smith-Rose, in co-operation with S. A. Bowhill and J. W. King. (Proceedings of the 7th International Space Science Symposium, Vienna, 10-18 May, 1966.) Vol. 1: Pp. xviii + 1-674. Vol. 2: Pp. xiv +6751479. (Amsterdam: North-Holland Publishing Co., 1967.) 180 guilders; $360 s$.

These two volumes comprise papers, or abstracts of papers, read at the Seventh International Space Science Symposium in May 1966. The first volume incorporates papers on interactions between the neutral and ionized parts of the atmosphere, together with some on the latest significant result on the ionosphere and airglow and on the magnetosphere, radiation belts, and aurora. The second volume covers tracking, telemetry, and dynamics of satellites, polar cap experiments, the Earth's neutral atmosphere and exosphere, together with solar X-rays, ultraviolet radiation, cosmic radiation, and a section headed "Real Time Transmission", which includes papers on solar X-rays and ionospheric irregularities. Finally, there is a section headed "Miscellaneous", which is mainly concerned with meteoric matter but includes items on the world magnetic survey and the Gemini experiments. Papers on the Moon and planets and life sciences and space research will appear in two further volumes.

Browsing through this fifteen hundred pages or so of scientific hodge-podge, one cannot help but question the wisdom of publishing in two large and expensive volumes such a wide variety of specialized papers whose common ground, where this exists at all, is the use of rocket and satellite technology. The idea of a symposium on "Space Science" which lumps together otherwise completely unrelated subjects, like gravity surveys, propagation of solar flare particles through interplanetary space, and collection of cosmic dust by balloons, seems to me to be a questionable one.

Publication of conference proceedings is in general justifiable provided that two conditions are met: first, the published record should provide an up-to-date and convenient summary of the current state of a particular field; and second, it should provide a record of comments, questions and answers which is unlikely to appear anywhere else even though the papers often do. Unfortunately, these two volumes do neither of these thingsthe field covered is too broad and there is an insufficient number of review papers for the first requirement to be met and no discussion is included except for one brief summary.

On the credit side, that part of the first volume which is devoted to the newly developing subject of the relations between the upper levels of the neutral atmosphere and the lower levels of the ionosphere does achieve some degree of homogeneity. It provides a useful collection of papers, including reviews, on general circulation, tidal oscillations and turbulence in the neutral atmosphere, ionospheric winds, sporadic E, photo-chemistry and stratosphereionosphere coupling effects.

To have produced these volumes in the time available is, of course, a great achievement, and both the editor and the publishers are to be complimented on the very high standard of reproduction. Nevertheless, readers will have no difficulty in finding a few misprints, of which two rather charming examples are the reference to "unvaluable co-operation by NASA" on page 1136 and to "neutral ion production" on page 1226. Bearing in mind the short time lapse between the conference and printing, it is surprising that there are not far more. H. ELLIOT

\section{LASERS IN TRANSLATION}

\section{Lasers}

By Karel Pátek. English translation edited by V. W. Rampton. Pp. 288. (London: Iliffe Books, Ltd. ; Prague: SNTL-Publishers of Technical Literature, 1967.) 45s. net.

THE recent burst of publication of books on lasers is added to by this English translation of the original Czech edition first published in 1964. Although described by the publishers as being intended for the specialist working with lasers or their applications, the contents and presentation are equally suitable for final year undergraduate students undertaking advanced courses in modern optics.

After an excellent, concise introduction covering the basic physics and history of the laser, gas, solid state and injection systems are treated in detail. The chapter on resonant cavities, probably the most difficult concept for the student, is particularly thorough, but the chapter on noise and monochromaticity has only three pages. Furthermore, the coherence properties of lasers, the essential feature distinguishing them from thermal light sources, receive scant treatment, and then only incidentally. Applications to communications and ranging, welding and drilling and in biology and medicine are well covered in the closing chapters.

Dispersed throughout the text there are several excellent summarizing tables, but unfortunately the material is now somewhat dated. This is the main criticism of the book ("an enlarged and revised English edition first published in 1967") which makes no mention of such important developments of the last two years as mode locking and holography.

D. J. Bradley

\section{WORKING WITH TRITIUM}

\section{Tritium and its Compounds}

By E. Anthony Evans. Pp. xiii +44I. (London: Butterworth and Co. (Publishers), Ltd., 1966.) $100 s$.

IMPROVEMENTS in performance and availability of liquid scintillation counters in recent years have led to a rapid 